\title{
A Year of Innovation for Chinese Journal of Catalysis
}

The Chinese Journal of Catalysis will celebrate its 35th birthday in the coming year. In 2014, a total number of 241 English papers have been published, including 10 Communications, 209 Articles, and 13 Reviews. New types of manuscripts have been introduced to better capture and reflect the most recent development in the international catalysis community, which include 1 Essay, 2 Highlights, 3 Mini-Reviews, 2 Perspectives, and 1 Viewpoint.

Three themed special issues were published in 2014. The First one (Issue 5), was edited by Professors Tao Zhang, Avelino Corma, and Ferdi Schueth on the topic of Catalysis for Biorefineries. It was published in May 2014 and contained 20 contributions. The Second one (Issue 6), published in June including 24 contributions, covered Carbon in Catalysis with Professor Dangsheng Su being the guest editor. The last one was published in August with 16 papers focusing on Rare Earth Catalysis and was organized by Professor Guanzhong Lu. Furthermore, four special issues on currently hot topics are currently conceived and planned for 2015.

In July 2014, the Thomson Reuters released the 2013 SCI impact factor (IF), which stands for an average number of citations received per paper published in a journal during the two preceding years. The 2013 IF of Chinese Journal of Catalysis is 1.552 , which amounts to the highest number since it was indexed in the Science Citation Index (SCI) Expanded. The journal published a total number of 542 papers with 284 in English and 258 in Chinese in 2011-2012. It can be fully anticipated that the 2014 IF will increase as a larger portion of English papers were published in the journal in 2012-2013.

In October 2014, the Chinese Journal of Catalysis organized its Fifth Editorial Board with us (Can Li and Tao Zhang) as the new Editors-in-Chief. Six prominent catalytic scientists were invited to join us as Associate Editors, and around eighty experts in the field as Editorial Board members. Significant innovations are being made step by step. In particular, we together with Associate Editors will handle submitted manuscripts, including pre-screening, identifying referees, and making the final decision. The goal of the new Editorial Board is to turn Chinese Journal of Catalysis to a truly international one (preferably with an impact factor higher than 4.0) although the title remains "Chinese".

The ScholarOne manuscript system has been launched for Chinese Journal of Catalysis, which can improve the efficiency of the editorial management and increase the academic influence of the journal. This system is adopted by many international journals, and it will help referees and authors with a more efficient handling of manuscript workflow.

In 2015, the "Most Cited Paper Award" will be established for papers published in the past three years to show our appreciation, and this award is based on the citation statistics from the Web of Science. The authors of these papers will have a significant cash award and an award certificate issued by the Journal and signed by us. In the future, the "Best Referee Award" will be presented in terms of a cash reward and a certificate to honor referees who offer highly professional peer reviews and timely handling of manuscripts, constructive comments to authors, and judicious recommendations. The "Award for Authors Who Published the Greatest Number of Outstanding Articles", consisting of a certificate and fund gift, will recognize the authors who have provided a great number of excellent articles for the journal.

As 2015 is approaching with a promising start, we together with all the Editorial Board Members will try our best to invite more high quality papers; and the journal will continue to provide rapid publication services to the authors and readers. With the great support from our authors, referees, readers, and Editorial Board Members, Chinese Journal of Catalysis will surely become an increasingly important platform for the communication of new findings in catalysis research which will closely joint the Chinese Catalysis Society and the international catalysis community.

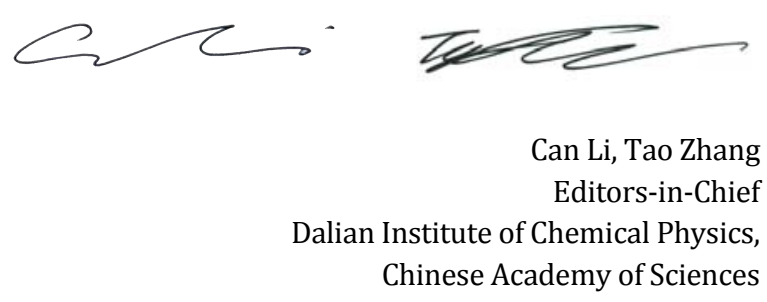

DOI: 10.1016/S1872-2067(14)60260-6 | http://www.sciencedirect.com/science/journal/18722067 | Chin. J. Catal., Vol. 36, No. 1, January 2015 (C) 2015, Dalian Institute of Chemical Physics, Chinese Academy of Sciences. Published by Elsevier B.V. All rights reserved. 